\title{
Modelling new production in the northwest Indian Ocean region
}

\author{
L. J. Watts ${ }^{1, *}$, S. Sathyendranath ${ }^{2,3}$, C. Caverhill ${ }^{2}$, H. Maass ${ }^{3}$, T. Platt ${ }^{2}$, N. J. P. Owens ${ }^{1}$ \\ ${ }^{1}$ Department of Marine Sciences and Coastal Management, Ridley Building, University of Newcastle Upon Tyne, \\ Newcastle Upon Tyne NE1 7RU, United Kingdom \\ ${ }^{2}$ Biological Oceanography Division, Bediord Institute of Oceanography, Dartmouth, Nova Scotia B2Y 4A2, Canada \\ ${ }^{3}$ Oceanography Department, Dalhousie University, Halifax, Nova Scotia B3H 4J1, Canada
}

\begin{abstract}
Oceanic new production is a potential avenue for the removal of atmospheric carbon dioxide to the deep abyss. The ability to estimate new production on large, ocean-basin scales has important implications for studies of the greenhouse effect. This paper describes the development of a method which will allow real-time estimates of new production on ocean-basin scales, given real-time data on ocean colour and sea-surface temperature from satellites. This study has concentrated on the northwest Indian Ocean region but the protocol developed could be geographically transportable. Results from a biogeochemical study carried out in the northwest Indian Ocean during a monsoon and an intermonsoon period in 1994 indicate that this region can be partitioned into 6 distinct provinces based on bathymetry, sea-surface temperature and chlorophyll measurements. Parameters that define the vertical structure in the biomass profile and the photosynthesis-light curve have been established for each province and these, in combination with archived satellite data, are used to compute the primary production for each province using an established light-dependent model. From our empirically derived relationship between the $f$-ratio and primary production, new production for the northwest Indian Ocean over these 2 different seasons is computed.
\end{abstract}

KEY WORDS: New production $\cdot f$-ratio $\cdot$ Primary production - Biogeochemical provinces $\cdot$ Satellite remote sensing $\cdot$ Modelling $\cdot$ Northwest Indian Ocean

\section{INTRODUCTION}

Over the last decade, concern about human interference with the earth-climate system has emphasized the need for a greater understanding of the global carbon cycle. This includes the oceanic component. The concept of 'new production' plays a central and fundamental role in our understanding of the role of the global ocean in the planetary carbon cycle.

The basic concept and definition of new production was formally introduced by Dugdale \& Goering (1967), who defined it as that portion of phytoplankton production in a given area that is supported by the input of 'new' nitrogen, such as nitrate and dinitrogen gas, from outside the boundaries of the area. Nitrate from

-E-mail: l.j.watts@ncl.ac.uk below the photic zone is one major source of this nitrogen (Platt et al. 1992) whereas dinitrogen gas can only be considered a major source if there are nitrogenfixing organisms present (e.g. Karl et al. 1997, Letelier $\&$ Karl 1996). The remainder of the primary production is referred to as regenerated production and is dependent on reduced nitrogen derived from the excretion of organisms and microbial activity in the photic zone (Platt et al. 1992).

New production is arguably one of the most important conceptual models formulated in biological oceanography since it is the force behind the 'biological pump'. The 'biological pump' refers to the process by which nitrogen and carbon are exported from the surface layers of the ocean to the ocean interior as sinking organic particles, and in the dissolved organic forms, transported by ocean currents. In a steady state system this export of organic carbon and nitrogen must 
be balanced by an equivalent input back into the photic zone (Williams 1998). This occurs primarily by advective and diffusive transport of dissolved nitrate from the ocean interior up into the photic zone where it can be assimilated by phytoplankton during new production. Measuring new production therefore allows us to quantify the export production and hence to estimate the potential (that is, the upper limit) of the oceans to remove atmospheric carbon to the deep abyss. In this context new production has been described as 'a mechanism by which man hopes the pollution of the atmosphere will be swept under the rug of the thermocline' (Platt et al. 1992).

The main aim of this study was to develop a method for estimating new production on large, ocean-basin scales. Attempts to achieve this with conventional methods such as shipboard experiments are frustrated by the low cruising speed of research ships, leading to extreme undersampling and inadequate spatial resolution. The only possible avenue to synoptic biological oceanography at this scale is via remote sensing techniques, since such measurements achieve the necessary coverage with acceptable spatial resolution at the surface (Platt \& Sathyendranath 1988). This approach has been taken by previous workers to estimate new production in localised areas such as the Georges bank region (Sathyendranath et al. 1991), an upwelling regime off the northwest coast of Africa (Dugdale et al. 1989) and a Californian coastal upwelling area (Dugdale et al. 1997), but not on ocean-basin scales.

The methods developed in this study have incorporated satellite data and these have been linked to ship-board data through newly derived empirical algorithms

Given the main aim of the study, we have not discussed the oceanographic context of the findings; this is detailed in Watts \& Owens (1999).

\section{STUDY AREA}

This study has concentrated on the northwest Indian Ocean region but the methods and approach developed are not, in principle, limited to this area. Indeed, they have been designed to act as a template for new production estimates in other ocean basins, given favourable conditions for remote sensing techniques.

The northwest Indian Ocean basin was chosen because of the spatial and temporal diversity in biological productivity exhibited in this area YYentsch 1965, Brock et al. 1991, Sathyendranath et al. 1991, Burkill et al. 1993, Banse \& English 1994, Watts \& Owens 1999). Although it is one of the smallest ocean basins, it contains a diversity of oceanic environments: eutrophic, oligotrophic, upwelling and reduced-oxygen environments, making it an ideal location for a methoddevelopment study of a biogeochemical nature (Burkill et al. 1993). This diversity is caused by the seasonally reversing patterns in wind and currents: from late May through to September winds blow from the southwest, creating the southwest monsoon; from December through to February the winds reverse direction and blow from the northeast creating the northeast monsoon (Burkill et al. 1993). Intermonsoon transitions occur between October and November, March and May (Schott et al. 1990). During the monsoon seasons wind-induced upwelling occurs along much of the basin's coastline which gives rise to very high primary production. For example, along the northern, coastal boundaries, recorded rates of daily integrated production have been as high as $6 \mathrm{~g} \mathrm{C} \mathrm{m}^{-2} \mathrm{~d}^{-1}$ (Qasim 1982). Estimates of the $f$-ratio have been as high as 0.9 in these coastal regions (Owens et al. 1993, Watts \& Owens 1999) resulting in high levels of new production (calculated as the product of the $f$-ratio and primary production). This wind-induced upwelling is strongest during the southwest monsoon and, as such, has been the focus of a number of international, multidisciplinary expeditions (Wyrtki 1971, Zeitzschel 1973, Angel 1984, Burkill et al. 1993). As a result, some information is available on the primary production in this region during the monsoon periods (Krey 1973, Saijo 1973, Krey \& Babenerd 1976, Qasim 1982, Bauer et al. 1991, Owens et al. 1993) but is limited for the intermonsoon. Similarly, information on nitrogen assimilation during the intermonsoon period is very limited for this region (Watts \& Owens 1999).

This study has considered biological activity during both the monsoon and the intermonsoon seasons.

\section{METHODS AND APPROACH}

\section{Shipboard measurements}

Data were collected on 2 research cruises carried out in the northwest Indian Ocean region: (1) during the latter part of the southwest monsoon, from 27 August to 4 October 1994 (cruise D210) and (2) during an intermonsoon period from 16 November to 19 December 1994, (cruise D212). Both cruises were carried out aboard the RRS 'Discovery'.

The principal measurements made at sea were nitrogen assimilation rates of phytoplankton as described below. Supporting data collected concurrently and used in this study were primary production rates (Savidge \& Gilpin 1999), photosynthesis-irradiance (P-I) parameters (Sathyendranath et al. 1999), ambient nutrient concentrations (Woodward et al. 1999), CTD data (depth resolved temperature, salinity, chlorophyll 
biomass) and underwater light measurements; depthresolved photosynthetically active radiation (PAR) data (Pinkerton et al. 1999).

\section{Measurements of nitrogen assimilation rates}

For both the monsoon and the intermonsoon cruises, rates of nitrogen assimilation were measured using in vitro, ${ }^{15} \mathrm{~N}$ stable-isotope, tracer techniques. Measurements were made at stations (13 stations for the intermonsoon and 11 stations for the monsoon cruises) along a transect from the Gulf of Oman and the Arabian Peninsula, southwards to close to $8^{\circ} \mathrm{N}$ (Fig. 1). From these data the $f$-ratio was calculated. This is the ratio of new production to total production and there are currently several different methods by which to estimate it (see Bury et al. 1995). In the present study the $f$-ratio was calculated as the ratio of phytoplankton nitrate assimilation to the sum of nitrate, ammonium and urea assimilation, according to Dugdale \& Goering (1967) and Eppley \& Petersen (1979). The integrated $f$-ratio referred to in the text is calculated from data integrated over the depth of the phatic zone (depth at which there is $1 \%$ of the surface measured PAR).

Full details of the shipboard measurements can be found in Watts \& Owens (1999).

\section{Results of shipboard measurements}

Results from the nitrogen assimilation and primary production experiments are summarised in Table 1. A more detailed and descriptive account of the nitrogen assimilation results from the intermonsoon study can be found in Watts \& Owens (1999).

The spatial and temporal variations of new production with respect to intermonsoon and monsoon conditions in the study area, are shown in Fig. 1. In summary, the monsoon season shows much higher levels of primary production (average $1666 \mathrm{mg} \mathrm{C}$ $\mathrm{m}^{-2} \mathrm{~d}^{-1}$ ) than the intermonsoon (average $720 \mathrm{mg} \mathrm{C} \mathrm{m}{ }^{-2} \mathrm{~d}^{-1}$ ), much higher $f$-ratios (average 0.64 cf. 0.28 ) and, correspondingly much higher new production levels (average $1214 \mathrm{mg} \mathrm{C} \mathrm{m}^{-2} \mathrm{~d}^{-1}$ cf. $220 \mathrm{mg} \mathrm{C}$ $\mathrm{m}^{-2} \mathrm{~d}^{-1}$ ). This can all be attributed to the increased levels of wind mixing at the open, oceanward stations, and upwelling at the Arabian Sea coastal stations (AS stations), both of which occur during the monsoon seasons. This results in increased levels of new nitrogen (namely nitrate) being transported into the photic zone where it can be used in new production.

Whilst this type of data set is useful in that it extends the information available on new production for a particular area, it is limited in that it only gives information on conditions along a particular cruise track at a par-

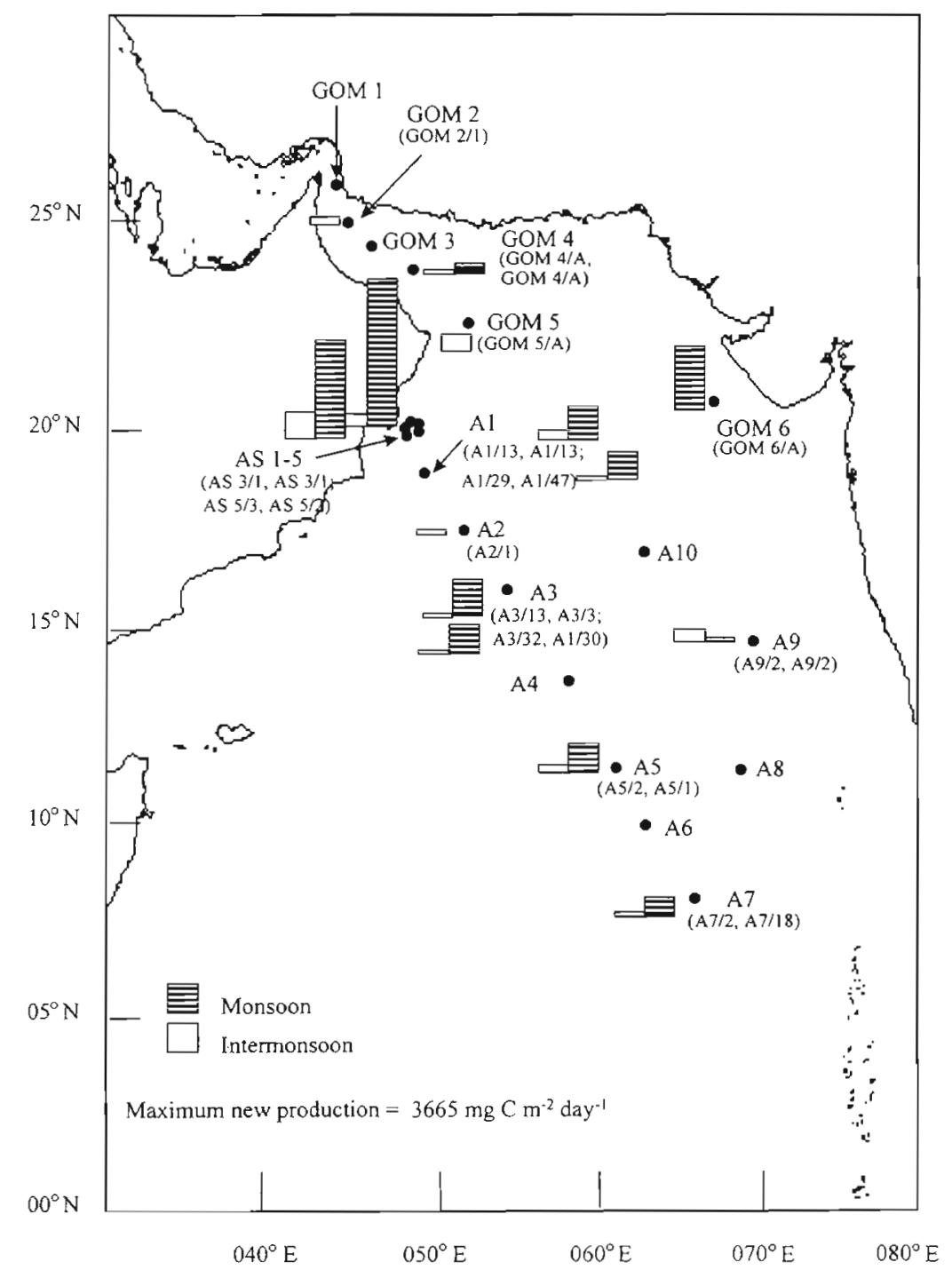

Fig. 1. Spatial and temporal variation in new production in the northwest Indian Ocean measured during the southwest monsoon (September 1994/ Cruise D210) and an intermonsoon period (November/December 1994/ Cruise 212). New production measurements are integrated over the depth of the photic zone (depth at which there is $1 \%$ of the surface irradiance). Cruise sites (e.g. A7) are labelled in larger font and station names at the particular site (e.g. A $7 / 2 ; A 7 / 18$ ) are in parentheses (intermonsoon station: monsoon station-see Table 1). CTD data were also collected at all stations at all sites 
Table 1. Total nitrogen assimilation by phytoplankton, integrated $f$-ratio and integrated primary production for the monsoon (cruise D210) and intermonsoon (cruise D212) seasons. Integrations are carried out over the depth of the photic zone (depth at which there is $1 \%$ of the surface irradiance). The photic zone depth is indicated in parentheses. (For further details see Watts \& Owens 1999)

\begin{tabular}{|c|c|c|c|}
\hline $\begin{array}{l}\text { Station } \\
\text { name }\end{array}$ & $\begin{array}{c}\text { Total } N \\
\text { assimilation } \\
\text { mmole } \mathrm{m}^{-2} \mathrm{~d}^{-1}\end{array}$ & $\begin{array}{l}\text { Integrated } \\
f \text {-ratio }^{b}\end{array}$ & $\begin{array}{c}\text { Integrated primary } \\
\text { production } \\
\text { mg C m } \mathrm{m}^{-2} \mathrm{~d}^{-1}\end{array}$ \\
\hline \multicolumn{4}{|c|}{ Monsoon cruise D210 } \\
\hline GOM 4/A & 3.1 & 0.22 & 726 \\
\hline GOM 6/A (30 m) & 9.5 & 0.82 & 1951 \\
\hline $\mathrm{A} 1 / 13(40 \mathrm{~m})$ & 2.9 & 0.70 & 1226 \\
\hline $\mathrm{A} 1 / 47(35 \mathrm{~m})$ & 6.0 & 0.47 & 1473 \\
\hline $\operatorname{AS~} 5 / 2(25 \mathrm{~m})$ & 15.0 & 0.96 & 3818 \\
\hline AS $3 / 1(25 \mathrm{~m})$ & 14.3 & 0.92 & 2668 \\
\hline $\mathrm{A} 3 / 30(60 \mathrm{~m})$ & 1.5 & 0.65 & 1119 \\
\hline $\mathrm{A} 3 / 3(27 \mathrm{~m})$ & 3.2 & 0.79 & 1135 \\
\hline $\mathrm{A} 5 / 1(100 \mathrm{~m})$ & 7.0 & 0.48 & 1529 \\
\hline A $7 / 18(75 \mathrm{~m})$ & 2.7 & 0.47 & 1013 \\
\hline $\mathrm{A} 9 / 2$ & 1.8 & 0.10 & 421 \\
\hline \multicolumn{4}{|c|}{ Intermonsoon cruise D212 } \\
\hline $\operatorname{GOM} 2 / 1(50 \mathrm{~m})$ & 20.4 & 0.25 & 798 \\
\hline GOM 4/A $(60 \mathrm{~m})$ & 4.3 & 0.07 & 704 \\
\hline GOM 5/A $(60 \mathrm{~m})$ & 5.1 & 0.41 & 1036 \\
\hline $\mathrm{A} 1 / 6(45 \mathrm{~m})$ & 2.9 & 0.33 & 766 \\
\hline $\mathrm{A} 1 / 29(45 \mathrm{~m})$ & 1.1 & 0.28 & 303 \\
\hline AS $3 / 1(45 \mathrm{~m})$ & 1.7 & 0.52 & 1256 \\
\hline AS $5 / 3(30 \mathrm{~m})$ & 7.5 & 0.33 & 1024 \\
\hline A2/1 (50 m) & 1.9 & 0.17 & 738 \\
\hline $\mathrm{A} 3 / 13(80 \mathrm{~m})$ & 5.6 & 0.24 & 281 \\
\hline $\mathrm{A} 3 / 32(80 \mathrm{~m})$ & 8.8 & 0.20 & 462 \\
\hline $\mathrm{A} 5 / 2(80 \mathrm{~m})$ & 18.2 & 0.23 & 814 \\
\hline A7/2 $(80 \mathrm{~m})$ & 6.8 & 0.21 & 518 \\
\hline A9/2 (100 m) & 23.6 & 0.41 & 751 \\
\hline
\end{tabular}

ticular time. If we want to consider new production on ocean-basin scales, we need to find a way of extrapolating these discrete ship-board observations to much larger horizontal scales. As mentioned in the 'Introduction', remotely sensed data can act as a vehicle for such extrapolations and this is now considered.

\section{Extrapolation to large horizontal scale: use of remotely sensed data}

Sea-surface properties that have a particular expression in the electromagnetic spectrum can be successfully measured by remote sensing. For example, phytoplankton concentration (biomass/chlorophyll) in the surface layer of the oceans can be calibrated against remotely sensed ocean colour data (Gordon \& Morel 1983, Hay et al. 1992), subsequently allowing the computation of regional- and basin-scale estimates of marine primary production (Platt \& Sathyendranath 1988, Morel \& André 1991, Platt et al. 1991, Sathyendranath et al. 1995). New production, however, has no electromagnetic expression that can be exploited for direct measurement from satellites. Instead we have to explore indirect methods for its estimation when using remote sensing techniques (Sathyendranath et al. 1991 Kudela \& Dugdale 1995, Dugdale et al. 1997).

Since it is possible to estimate primary production on ocean-basin scales by incorporating remotely sensed satellite data into computer models (Platt \& Sathyendranath 1988, Sathyendranath \& Platt 1989, Morel \& André 1991, Platt et al. 1991, Sathyendranath et al. 1991, Brock et al. 1993, Platt et al 1995, Sathyendranath et al. 1995), the following protocol has been followed and developed during this study: (1) choose an appropriate local model to compute primary production for the study area; (2) develop a protocol for its extrapolation to ocean-basin scales; (3) compute primary production on these scales; (4) derive an empirical relationship for the estimation of basin scale new production from the computed primary production; and (5) estimate new production on such scales. Where possible, computed data have been validated by comparison with independent data sets.

\section{The model}

The model we have chosen for computation of primary production is the 'local algorithm' described in Platt \& Sathyendranath (1988) in its most recent version, as presented in Sathyendranath et al. (1995). In this model, primary production is expressed as a function of biomass, $B$, and available light, $I$. Chlorophyll concentration is chosen to indicate phytoplankton biomass because of the central role it plays in photosynthetic processes and because it is the biological variable that is most easily monitored from space (Sathyendranath \& Platt 1993), from ocean colour data. Available light at the sea-surface in the photosynthetically active waveband (400 to $700 \mathrm{~nm}), I_{0}(t)$, is a function of time, $t$, and can be calculated (Bird 1984) assuming that the sky is free of clouds. The effect of clouds can then be allowed for using representative data on cloud cover. By describing the vertical distribution of chlorophyll concentration (the depth-resolved biomass profile), the diffuse attenuation coefficient for downwelling light $(K)$ can be determined, as well as the 
amount of light available at depth $z$, for photosynthesis (Platt et al. 1995). Data collected in the Arabian Sea (Sathyendranath et al. 1999) were used to parameterise the spectrally resolved absorption coefficient of phytoplankton as a function of biomass $B$. (Note that phytoplankton absorption coefficient is a component of $K$ )

The depth-resolved biomass profile cannot be derived directly by remote sensing because satellites can only provide information on the near-surface layers of the sea, typically about one fifth of the productive part of the water column (Gordon \& McCluney 1975, Sathyendranath \& Platt 1993). Instead, it is derived by extrapolating the satellite-derived surface concentration of chlorophyll vertically downwards, the shape of the profile following a standardised vertical profile. A shifted Gaussian distribution function (Platt et al. 1988) is used to describe the shape of this profile (see 'Protocol' below, Fig. 4). Four of the parameters that describe this Gaussian function are empirically derived from in situ shipboard measurements of the chlorophyll profile (derived from fluorescence data collected by the CTD): the depth of the chlorophyll peak $\left(z_{\mathrm{m}}, \mathrm{m}\right)$, the standard deviation around the peak value $(\sigma, \mathrm{m})$, the total pigment within the peak ( $h, \mathrm{mg}$ $\left.\mathrm{m}^{-2}\right)$ and the background pigment $\left(B_{0}, \mathrm{mg} \mathrm{m}^{-3}\right)$. Other parameters computed for each profile were derived from the 4 independent parameters described above: $H$, the height of the peak above the background which is derived as $H=\left\{h /[\sigma(2 \pi)]^{05}\right\}$ and $\rho^{\prime}$, the ratio of peak height to total pigment at $z_{\mathrm{m}}\left[\left(\rho^{\prime}=H /\left(H+B_{0}\right)\right]\right.$ (Sathyendranath et al. 1995). We also computed $B_{\{0\}}$, the surface chlorophyll concentration.

The model also requires parameters of the photosynthesis-light (P-I) curve: the initial slope, $\alpha^{B}$, and the production at light saturation described by the assimilation number, $P_{\mathrm{m}}^{\mathrm{B}}$, where the superscripts indicate normalization to biomass B (Sathyendranath \& Platt 1993). These parameters are also derived from in situ shipboard measurements (Sathyendranath et al. 1999). Unlike previous studies (Platt et al. 1991, 1995, Sathyendranath et al. 1995), the P-I parameters used in this study are depth dependent (see 'Protocol' below).

Given all this information the model computes the instantaneous photosynthetic rate at depth $z$, which can then be integrated over time and depth to obtain daily, water-column primary production.

From the model description above, it is apparent that to compute primary production on large scales, satellite and in situ observations have to be combined. Therefore, we need to find a way of extrapolating in situ observations in space and time to match the satellite database. In other words, for every pixel on a satellite image being used to derive the surface chlorophyll concentration, we need to be able to assign parameters for the Gaussian function and the P-I curve described above. The model can then compute the daily watercolumn primary production for every pixel on the image and thus create a map of computed primary production for the study area, the spatial resolution being equal to the pixel size. The extrapolation scheme developed here is discussed below.

\section{Protocol for the assignment of parameters}

The ideal solution for assignment of parameters is to find a basin-scale relationship between remotely sensed properties, such as sea-surface chlorophyll concentrations or sea-surface temperature, and the parameters of interest. Satellite data can then be used directly in the model to predict parameters for every pixel. Such relationships were investigated first.

We concentrated on data collected in the monsoon season since the in situ data showed a greater degree of spatial heterogeneity for sea-surface properties than for the intermonsoon data. To obtain the Gaussian parameters that describe the chlorophyll profile, we used 136 chlorophyll profiles from Cruise D210 and we fitted a shifted Gaussian distribution function (Platt et al. 1988) to each measured profile. An absolute minimum statistical requirement for fitting a 4 -parameter function to a data set is that there be at least 6 data points (Sathyendranath et al. 1995) and every profile used had more than 6 depths. Profiles considered to be successfully fitted had also to meet the following criteria. To avoid implausibly high or low values for each parameter, the following constraints were imposed: $3 \sigma$ had to be less than the distance between the 2 sampling depths immediately above and below $z_{m} ; \sigma$ had to be greater than $1 \mathrm{~m}$; the pigment value at $z_{\mathrm{m}}$ could not differ from the maximum observed value by more than a factor of 2 ; and the unexplained variance between observed and fitted values had to be less than 15\% (Sathyendranath et al. 1995).

The relationship between observed sea-surface chlorophyll concentration (shipboard measurement) and $z_{\mathrm{m}}$, using all the monsoon data, was found to be significant $(p<0.05)$, with regression coefficients $\left(\mathrm{r}^{2}\right)$ of 0.4 and 0.6 for a linear and logarithmic relationship respectively. However relationships of $\sigma$ and $h$ with observed sea-surface chlorophyll data were much weaker with $r^{2}$ values of $<0.15$ and the relationship with $\sigma$ showing no statistical significance $(p>0.05)$. The relationships of these Gaussian parameters with observed sea-surface temperature were even weaker. It was therefore concluded that although the prediction of $z_{\mathrm{m}}$ from sea-surface chlorophyll data, and therefore from satellite ocean colour maps was possible, it was not ideal since the relationship between the 2 was 
so weak. The prediction of parameters, $\sigma$ and $h$ from sea-surface chlorophyll or sea-surface temperature data was concluded to be impractical, in agreement with Sathyendranath et al. (1995).

Since the universal approach was unsatisfactory, the approach we took for the assignment of Gaussian function and P-I parameters was that of partitioning the northwest Indian Ocean into a suite of 'biogeochemical provinces' (Platt \& Sathyendranath 1988, Mueller \& Lange 1989, Platt et al. 1991, Longhurst et al. 1995, Platt et a1. 1995, Sathyendranath et al. 1995, Brock et al. 1998), which formed a template upon which the parameters could be assigned. Biogeochemical provinces are based on the concept that rates of ecophysiological and biogeochemical processes (in particular the photosynthetic rate) are under physical control so that the ocean basin is partitioned by delineating those areas that have a common physical forcing (Platt et al. 1995). Because of the spatial and temporal variability of biological events, the provinces should have dynamic boundaries that respond to changes in the oceanographic forcing (Sathyendranath et al. 1995). For practical reasons it is desirable that the boundaries respond to features observable by remote sensing so that their location can be easily monitored. The criteria for partitioning into provinces was therefore developed by examination of the sea-surface chlorophyll and sea-surface temperature properties (both available from satellite imagery). We used data collected in the monsoon season (cruise D210) to develop the criteria, given the spatial heterogeneity of the in situ data. Once developed, the same criteria were applied to the intermonsoon data (D212).

It was found that if the in situ sea-surface data were combined with the bathymetric data (maximum depth, $z_{\max }$ ) corresponding to each station, then the stations fell into 6 groups (provinces), unique in their combination of sea-surface chlorophyll, sea-surface temperature (SST) and $z_{\max }$ properties. These provinces are described generally in Fig. 2 and their specific properties are listed below (intermonsoon criteria given in brackets):

Province 'HSST', containing data from stations with relatively high seasurface temperature properties; GOM 1, 2 and 3 (Fig. 1), characterised by the following properties: $2500 \mathrm{~m} \geq z_{\max }>$ $200 \mathrm{~m}$; SST $\geq 30^{\circ} \mathrm{C}$ (intermonsoon: SST $\geq 28^{\circ} \mathrm{C}$ )
Province 'SHLF', containing data from stations on the continental shelf/upwelling region; AS 4,5 (Fig. 1), characterised by the following properties: $z_{\max } \leq 200 \mathrm{~m}$; $\mathrm{SST}<25^{\circ} \mathrm{C}$ (intermonsoon criteria the same);

Province 'SLPE', containing data from stations on the continental slope; AS 1, 2, 3 (Fig. 1), characterised by the following properties: $2500 \mathrm{~m} \geq z_{\text {maxi }} \mathrm{SST}<30^{\circ} \mathrm{C}$ (intermonsoon: SST $<28^{\circ} \mathrm{C}$ );

Province 'Hi-BIO', containing data from stations with high surface biomass concentrations; GOM 6 (Fig. 1), characterised by the following properties: $z_{\max } \geq 2500 \mathrm{~m}$; sea-surface chlorophyll concentration $>0.9 \mathrm{mg} \mathrm{m}^{-3}$ (intermonsoon criteria the same);

Province 'OCNS', containing data from southern oceanic stations A6, 7, 8, 9 (Fig. 1) characterised by the following properties: $z_{\max } \geq 3975 \mathrm{~m}$; SST $\geq 27^{\circ} \mathrm{C}$; sea-surface chlorophyll concentration $\leq 0.3 \mathrm{mg} \mathrm{m}^{-3}$ (intermonsoon sea-surface chlorophyll concentration $\leq 0.2 \mathrm{mg} \mathrm{m}^{-3}$ );

Province 'OCNN', containing data from more northerly oceanic stations A1,2,3,4,5,10, GOM 4, 5 (Fig. 1): This province is characterised by $z_{\max } \geq$ $2500 \mathrm{~m}$, intermediate sea-surface chlorophyll concentrations; SST $<27^{\circ} \mathrm{C}$ (intermonsoon criteria the same). It is a province for those pixels which do not fall into the 'Hi-Bio' province or the warmer, more oligotrophic 'OCNS' province.

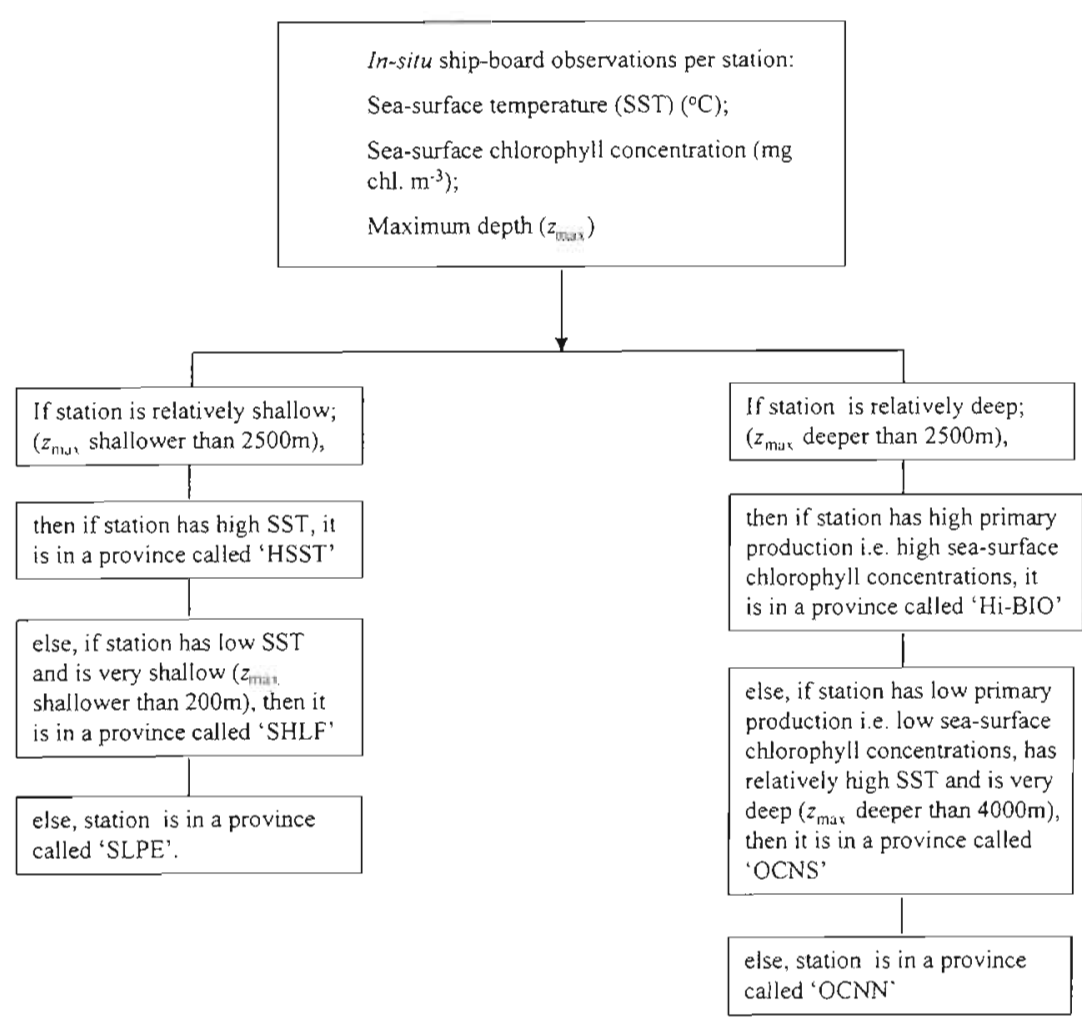

Fig. 2. Flow diagram showing generalised partitioning of provinces given in situ ship-board measurements of sea-surface properties and bathymetry data 
Defining the provinces in this way meant that the areas of each province could be determined by combining satellite images of sea-surface chlorophyll and SST, with bathymetric maps, all gridded to the same resolution, and assigning each pixel to a province, using the criteria listed above. The next step was to obtain relevant satellite data:

At the time this study was made, the ocean colour data available (for derivation of sea-surface chlorophyll concentrations) were Coastal Zone Color Scanner (CZCS) data. These archived data exist only for the period 1978 to 1986, and, even within this window, coverage of the global ocean is uneven in time and space. Sea-surface temperature data (AVHRR; advanced very high resolution radiometer) collected between 1981 and 1986 were available for this study. The year that gave the best coverage of the study area by both CZCS and AVHRR was 1984 and so composite monthly images of CZCS, co-registered with AVHRR, were obtained from the NASA Physical Oceanography Distributed Active Archive Center at the Jet Propulsion Laboratory, California Institute of Technology (Tran et al. 1992), for the months of September (monsoon), November and December (intermonsoon) for that year. The area covered by the images was $0^{\circ}$ to $30^{\circ} \mathrm{N}$ and $32^{\circ}$ to $90^{\circ} \mathrm{E}$ and interpolated data were used to fill in the missing values. The images had a resolution of 18 by $18 \mathrm{~km}$ at the equator and data were presented on an equal angle grid. Bathymetry data (the ETOPO5 dataset, courtesy of The Geological Sciences Division, Cornell University, Ithaca, U.S.) were re-gridded to match the resolution of the satellite maps.

Each pixel on the satellite images, was then assigned to a province using the criteria described, so that the extent of each province i.e. the position of its boundaries could be determined. This is illustrated for the monsoon month of September in Fig. 3.

The criteria developed for the partitioning of provinces during the monsoon and intermonsoon seasons, can be used for any set of ocean colour and SST satellite imagery obtained during those seasons and, ideally, with real-time co-registered imagery to give real-time positions of the province boundaries. These boundaries are therefore dynamic, responding to features observable by remote sensing techniques. This is a major difference to the work done by Longhurst et al. (1995) where, although the need for dynamic boundaries was recognised, their implementation did not allow it. Brock et al. (1998) use surface biomass concentrations to classify biogeochemical provinces on the basis of light attenuation properties, so that the boundaries can be determined from remotely sensed ocean colour. In this sense, the Brock et al. (1998) work is similar to ours, though there are differences in the details of the implementation. For example, we use SST along with ocean colour and bathymetry data to disseminate between provinces, unlike Brock et al. (1998) who only use ocean colour.

Having assigned each pixel to a province, the next step was to determine the average shifted Gaussian (chlorophyll profile) and P-I parameters representative of each province. These parameters were required as input to the local algorithm model for computation of primary production.

The average shifted Gaussian parameters were obtained by binning and averaging the Gaussian parameters obtained by fitting the shifted Gaussian distribution function (Platt et al. 1988) to each measured
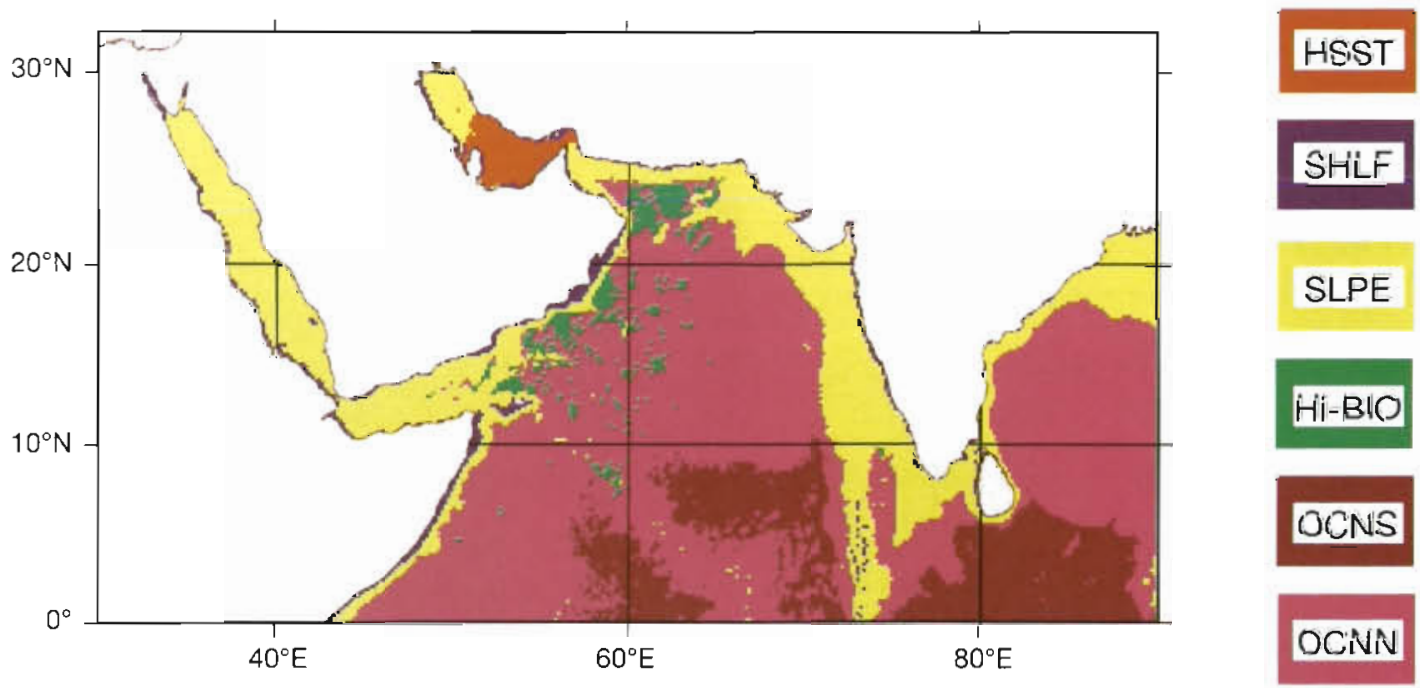

Fig. 3. Areas occupied by the 6 biogeochemical provinces identified in this study for the north-west Indian Ocean basin, for the monsoon month of September 

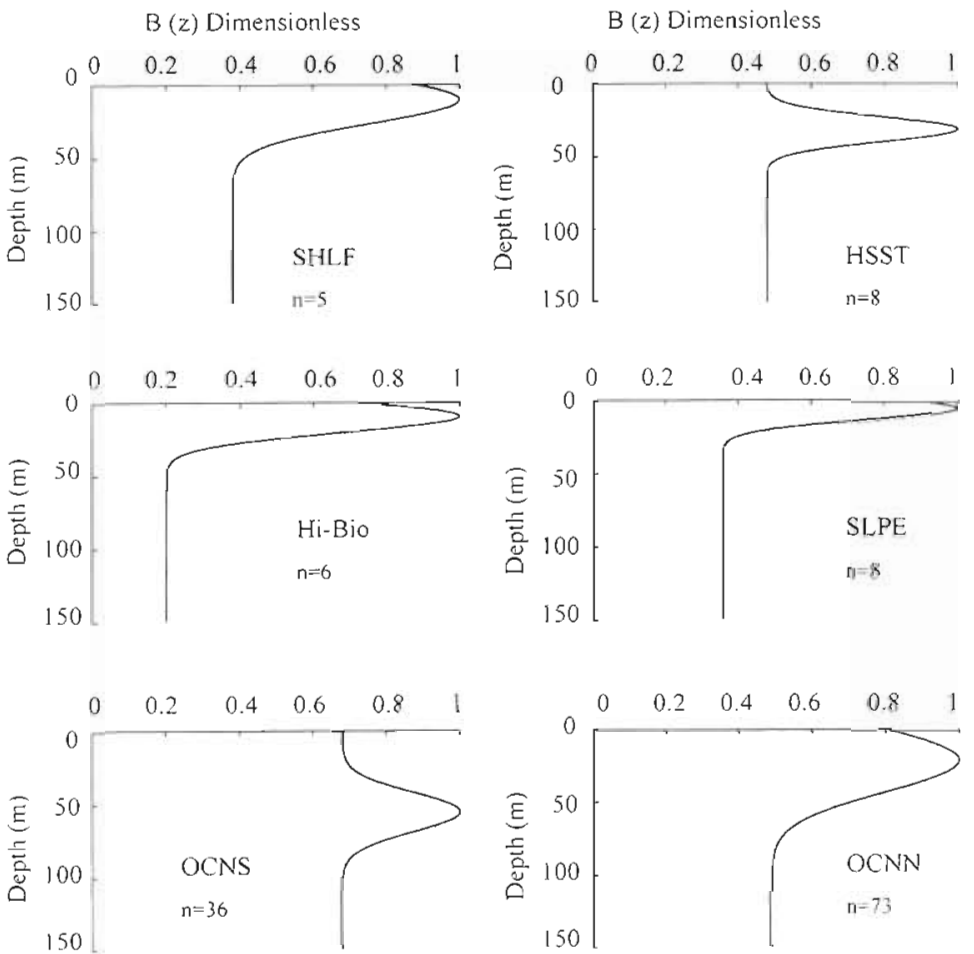

Fig. 4. September generalised biomass profiles for each of the 6 biogeochemical provinces, fitted using a shifted Gaussian distribution function ( $\mathrm{n}=$ number of chlorophyll profiles from which the generalised biomass profile is derived). Note that all profiles are scaled to one at $z_{\mathrm{m}}$. For each pixel, the absolute profiles are determined by using the satellite-derived ocean-colour data to provide the scaling factor

chlorophyll profile, as already described (136 chlorophyll profiles for cruise D210 and 92 for cruise D212). These were used to describe the shape of the standardised vertical biomass profile for each province (see Fig. 4). They were also used in statistical analyses to check that the criteria developed for the partitioning of provinces was robust.

The P-I parameters were assigned as follows. For every station we had available 2 values of $\alpha^{B}$ and $P_{\mathrm{m}}^{\mathrm{B}}$ i one set measured at $10 \mathrm{~m}$ depth and the other from the depth of the observed chlorophyll maximum. Available from cruise D210 were 108 sets of P-I data and from D212, 83 sets. Statistical analyses of the data showed that for each season, treating the data as a whole (i.e. not per province), $P_{\mathrm{m}}^{\mathrm{B}}$ showed a significant (at the $5 \%$ level) but weak $\left(\mathrm{r}^{2}=\right.$ 0.3 and 0.4 for D210 and D212 respectively) inverse relationship to depth (normalised to the depth of the photic zone). The parameter $\alpha^{B}$ was invariant with depth for both seasons, in agreement with Sathyendranath et al. (1995). We decided to make use of all the data available and the P-I parameters were binned and averaged per province (as for the shifted Gaussian parameters), for use in the local algorithm model (Platt \& Sathyendranath 1988, Sathyendranath et al. 1995). The model was then set up to apply shallow P-I parameters from the sea-surface to depths of $\left(z_{m}-2 \sigma\right)$ and to apply the deeper parameters from $\left(z_{m}-2 \sigma\right)$ to the base of the photic zone, so that the 'deep' parameters were applied to the entire deep chlorophyll peak. The P-I parameters used are listed in Table 2.

As mentioned, the average shifted Gaussian parameter values were also used for statistical analyses of the stability of the province boundaries. We restricted these analyses to the 3 parameters: $z_{m}, \sigma$ and $\rho^{\prime}$ since these are the parameters that are used in conjunction with surface chlorophyll from the CZCS images in the local algorithm approach (Platt \& Sathyendranath 1988, Sathyendranath et al. 1995). Inspection of the relative variance of means (coefficient of variance, $\mathrm{CV}$ ) for each average Gaussian parameter value, indicates a relatively low variance of the means (Sathyendranath et al. 1995) so that we can place a high confidence on their values: $\mathrm{CV}$ values for $z_{m}$ range between 0.07 and $0.43 ; \sigma$ from 0.16 to 0.82 and $\rho^{\prime}$ from 0.06 to 0.36 for $\mathrm{D} 210$. The corresponding values for D212 are 0.07 to $0.37 ; 0.16$ to 1.07 and 0.04 to 0.41 respectively.

Table 2. Mean shallow and deep P-I parameters used per season for each province. The parameter $P_{m}^{B}$ is in $\mathrm{mg} \mathrm{C}\left(\mathrm{mg} \mathrm{chl}^{-1} \mathrm{~h}^{-1}\right.$ and $\alpha^{\mathrm{B}}$ is in $\mathrm{mg} \mathrm{C}$ $(\mathrm{mg} \mathrm{chl})^{-1} \mathrm{~h}^{-1}\left(\mathrm{~W} \mathrm{~m}^{-2}\right)$

\begin{tabular}{|lcccc|}
\hline Province name & $P_{\mathrm{m}}^{\mathrm{B}}$ (shallow) & $P_{\mathrm{m}}^{\mathrm{B}}$ (deep) & $\alpha^{\mathrm{B}}$ (shallow) & $\alpha^{\mathrm{B}}$ (deep) \\
\hline Monsoon cruise $(\mathrm{D} 2$ 10) & 5.46 & & & \\
HSST & 4.58 & 1.96 & 0.08 & 0.05 \\
SHLF & 5.07 & 4.38 & 0.10 & 0.07 \\
SLPE & 2.99 & 1.24 & 0.11 & 0.11 \\
Hi-BIO & 5.23 & 2.33 & 0.07 & 0.05 \\
OCNS & 5.12 & 3.90 & 0.11 & 0.07 \\
OCNN & 8.39 & 4.11 & 0.10 & 0.09 \\
Intermonsoon cruise & (D212) & & 0.15 & \\
HSST & 8.43 & 7.01 & 0.15 & 0.11 \\
SHLF & 8.10 & 5.02 & 0.13 & 0.11 \\
SLPE & 2.99 & 1.82 & 0.07 & 0.05 \\
Hi-BIO & 5.11 & 2.24 & 0.18 & 0.15 \\
OCNS & 6.34 & 5.02 & 0.11 & 0.13 \\
OCNN & & & & \\
\hline
\end{tabular}


These mean parameter values were also used to check that the province boundaries were statistically significant: differences in $z_{\mathrm{m}}$ between adjacent provinces were significant at the $5 \%$ level for 6 out of 8 cases for D210 data (and 7 out of 9 for D212) but for only 4 cases out of 8 for $\sigma$ ( 3 out of 9 for D212) and 3 cases out of 8 for $\rho^{\prime}$ ( 3 out of 9 for D212). However, for every province there was at least 1 parameter that was significantly different from those in the adjacent provinces and for 4 cases out of 8 ( 2 out of 9 for D212) there were at least 2 parameters that were significantly different. These statistics satisfied us that the province boundaries were acceptable and the protocol developed for assigning them was robust.

The next step was to compute primary production for the northwest Indian Ocean basin.

\section{Primary production in the northwest Indian Ocean}

Primary production was computed for the months of September, November and December for each pixel on the satellite images (see 'Protocol' above). The seasonal mean values of $z_{\mathrm{m}}, \sigma$ and $\rho$ ' were used along with the satellite data, to derive the chlorophyll profile at each pixel (Longhurst et al. 1995, Sathyendranath et al. 1995). Combining these with the seasonal mean P-I parameters described in 'Protocol' and inputting them into the spectrally resolved version of the model as described in 'The model' and in Platt et al. (1991) and Sathyendranath et al. (1995), the primary production integrated to the depth of the photic zone was computed for each pixel. Fig. 5 illustrates the results of this computation for the monsoon month of September.

A statistical comparison of our computed primary production data with an independent data set $(\mathrm{n}=10)$ of ship-board primary production measurements collected in September 1986 (Owens et al. 1993) in the same area, gave good results of a significant positive linear regression with $r^{2}=0.89$ and slope $=0.72$. This means that the correlation between the 2 data sets was very high (89\%), although the computed primary production estimates for 1984 were on average $25 \%$ lower than the observations made in 1986 at the same locations. Since the computations were carried out for a particular year, and the independent data for the validation of the results came from another year, we can only say at this stage that this observed agreement between computations and observations is surprisingly good, especially since the northwest Indian Ocean is a highly dynamic environment with pronounced interannual variability (Yentsch 1965, Banse \& English 1994, Brock et al. 1991, Sathyendranath et al. 1991, Burkill et al. 1993, Watts \& Owens 1999).
We estimated monsoon (September) daily primary production for the area illustrated in Fig. 5 (eastern boundary $78^{\circ} \mathrm{E}$ ) to be $57 \times 10^{11} \mathrm{~g} \mathrm{C} \mathrm{d}^{-1}$. Intermonsoon daily primary production for the same area is estimated at $34 \times 10^{11} \mathrm{~g} \mathrm{C} \mathrm{d}^{-1}$ and $32 \times 10^{11} \mathrm{~g} \mathrm{C} \mathrm{d}^{-1}$ for November and December respectively. If we assume a total of 212 monsoon days (December to February and June to September) and 153 intermonsoon days and extrapolate the computed estimates from this study, we get a crude estimate of annual primary production for this area of $1.7 \mathrm{GT} \mathrm{C} \mathrm{yr}^{-1}$. This agrees well with the esti-

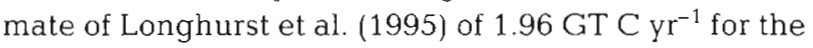
Red Sea, Persian Gulf, Arabian Sea and western Indian continental shelf combined.

Empirical relationship for new production estimation

Once the primary production was computed on the ocean-basin scale, the next step was to derive an empirical relationship for the estimation of new production on the same geographical scale. We decided to use the logarithmic relationship (see Fig. 6) observed between the $f$-ratio computed for the production and integrated primary production for data collected in 1986 (Owens et al. 1993) and on cruises D212 and D210 in the north west Indian Ocean. This relationship was found to be significant with an $\mathrm{r}^{2}=0.75$ and was described by the equation: $y=0.3496 \ln (x)-1.965$, where $y=$ integrated $f$-ratio and $x=$ integrated primary production $\left(\mathrm{mg} \mathrm{C} \mathrm{m}^{-2} \mathrm{~d}^{-1}\right.$ ).

\section{New production in the northwest Indian Ocean}

We could now estimate new production on an oceanbasin scale, using the above relationship. New production was calculated as the product of the integrated primary production and the integrated $f$-ratio, as determined through the relationship shown in Fig. 6. This calculation was carried out for every pixel in Fig. 5 and also for the intermonsoon season. The map obtained for new production in September is shown in Fig. 7.

A statistical comparison of the computed $f$-ratio data with observations $(n=10)$ collected in September 1986 (Owens et al. 1993) in the same area, gave good results: (although the observed data from Owens et al. 1993 cannot be strictly described as an independent data set, we felt it could be used in this comparison because the logarithmic relationship described in Fig. 6 varied insignificantly with exclusion of this data set). The comparison showed a significant positive linear relationship between the computed $f$-ratio and the observed (independent variable) data, with $r^{2}=0.81$ and slope $=0.55$. Thus the correlation between the 


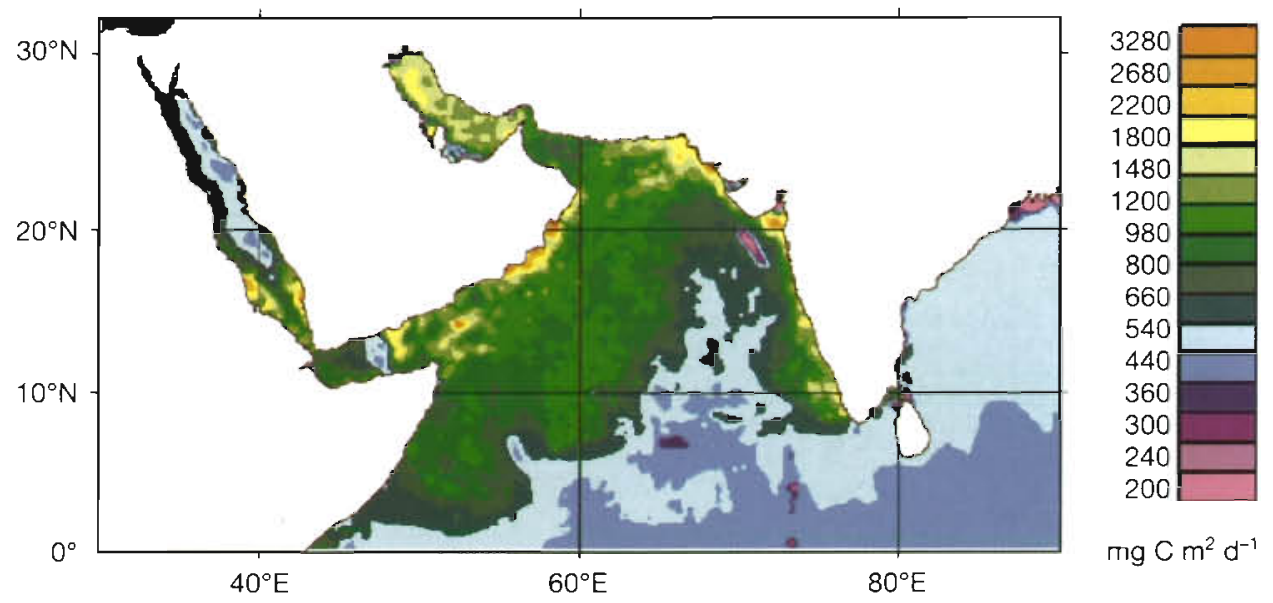

Fig. 5. Estimated primary production $\left(\mathrm{mg} \mathrm{C} \mathrm{m} \mathrm{m}^{-2} \mathrm{~d}^{-1}\right.$ ) for the northwest Indian Ocean, computed as described in the text for September 1984. The model parameters are partitioned by 6 biogeochemical provinces defined by sea-surface temperature, sea-surface chlorophyll concentration and bathymetry, as described in 'Protocol' in the text

2 data sets was high. The slope, which suggests that the $f$-ratio in 1984 was $55 \%$ of that observed at the same location in 1986, is a direct consequence of the fact that the computed total primary production for 1984 is lower than the measurements of 1986 by $25 \%$ on average.

We estimated monsoon (September) new production for the area illustrated in Fig. 7, (eastern boundary at $78^{\circ} \mathrm{E}$ ), to be $21 \times 10^{11} \mathrm{~g} \mathrm{C} \mathrm{d}^{-1}$. Intermonsoon new production for the same area is estimated at $67 \times 10^{10} \mathrm{~g} \mathrm{C}$ $\mathrm{d}^{-1}$ and $53 \times 10^{10} \mathrm{~g} \mathrm{C} \mathrm{d}^{-1}$ for November and December respectively. If we assume a total of 212 monsoon days (December to February and June to September) and 153 intermonsoon days and extrapolate the computed

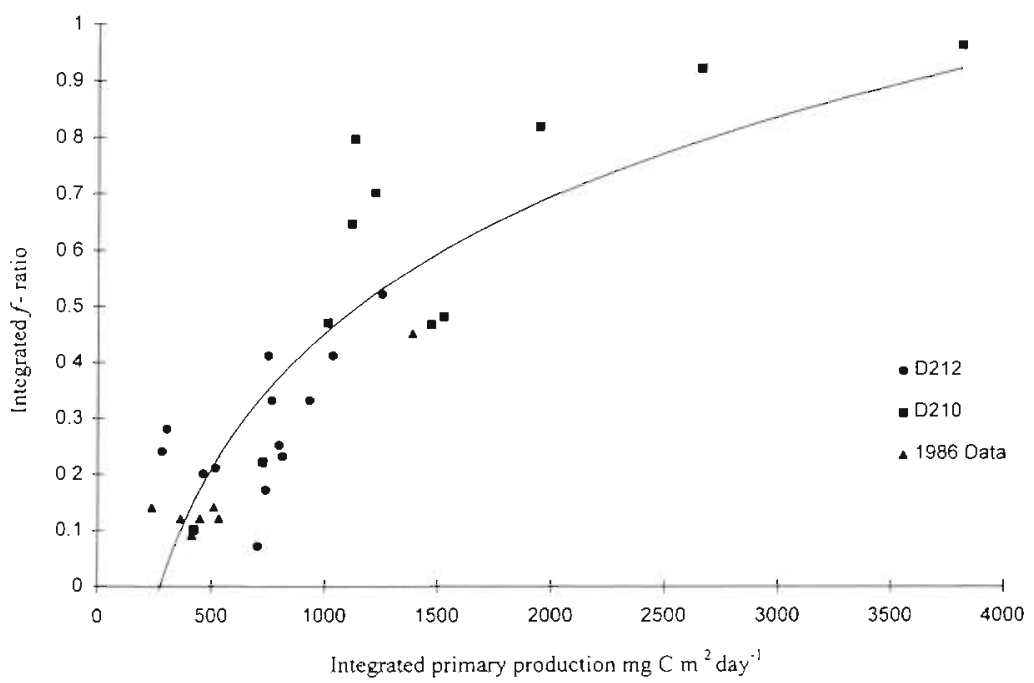

Fig. 6. Empirically derived relationship between the integrated $f$-ratio and integrated primary production for the northwest Indian Ocean region. Data collected from 1986 cruise (Owens et al. 1993) and cruises D210 and D212 (Table 1) estimates from this study, we get a crude estimate of annual new production for this area of $0.5 \mathrm{GT} \mathrm{C} \mathrm{yr}^{-1}$ that is, approximately, $30 \%$ of the total annual primary production for the area.

\section{CONCLUSIONS}

We have presented a statistically robust method for partitioning the northwest Indian Ocean region based on the knowledge of bathymetry, surface temperature and chlorophyll concentration for this area. The motivation for this partitioning was to facilitate the computation of primary and new production on large horizontal scales. This we have achieved by taking into account the vertical structure of the chlorophyll profile and the depthdependent relationship of the P-I parameters, in our calculations.

The general method presented here, of combining remotely sensed data and observations via simple empirical relationships, should be applicable to other geographical regions (given favourable conditions for remote sensing techniques). Although our algorithm linking the $f$-ratio to production (Fig. 6) was robust over both the monsoon and intermonsoon seasons, it may be found that for other geographical areas this type of relationship may change with season i.e. quantitative relationships should be established specifically for the region of application.

With the launch of the SeaWiFs satellite and other ocean colour sensors in 

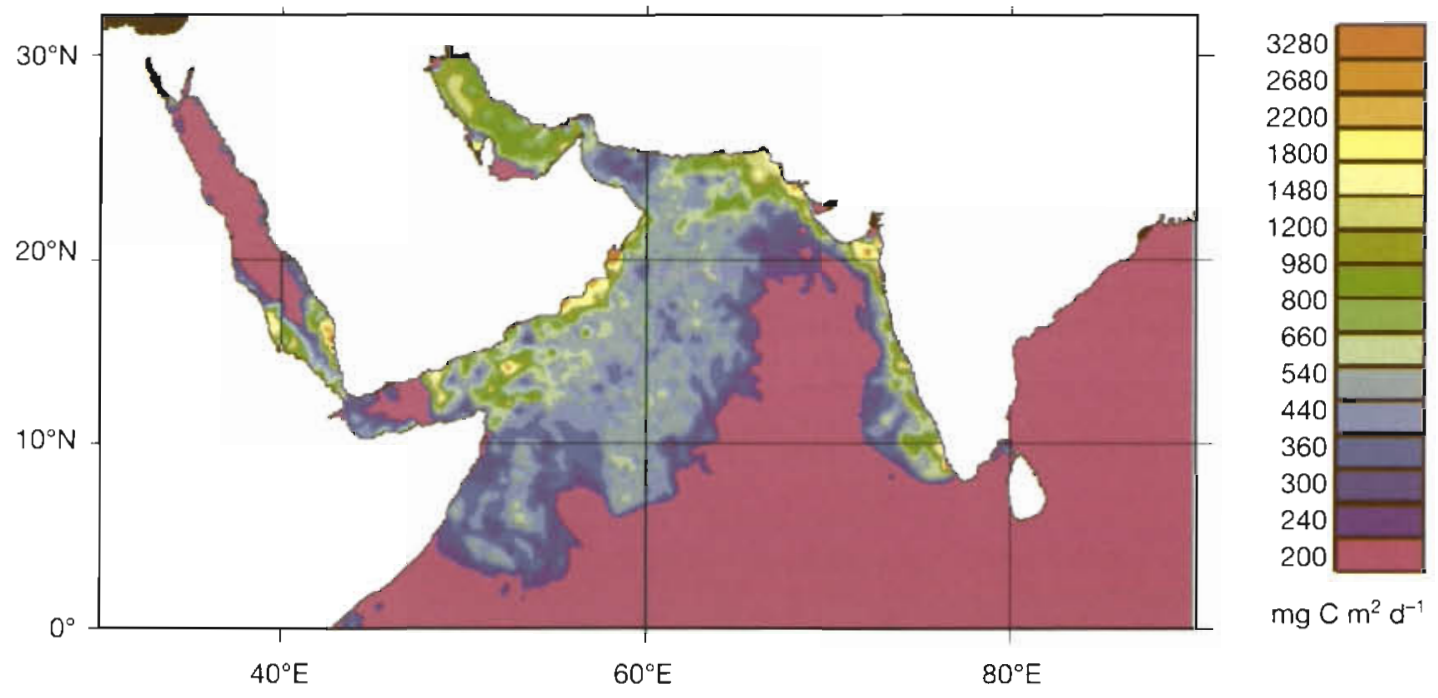

$\mathrm{mg} C \mathrm{~m}^{2} \mathrm{~d}^{-1}$

Fig. 7. Estimated new production $\left(\mathrm{mg} \mathrm{C} \mathrm{m}^{-2} \mathrm{~d}^{-1}\right.$ ) for the northwest Indian Ocean for September 1984

the last $2 \mathrm{yr}$, and the continuing availability of the NOAA-series of satellites with AVHRR sensors, it should be possible to gain access to real-time ocean colour and sea-surface temperature satellite data, when undertaking such studies in the future. What we lack are sufficient ship-board observations with which to calibrate the algorithms developed for applications of remotely sensed data. We therefore suggest that more effort should be directed towards collecting global P-I, primary production and new production data, all following the same protocol at sea, for investigation of estimation of new production on the global scale.

Acknowledgements. The authors wish to thank the numerous people who have helped to make this work possible: Venetia Stuart for contributing optics data, Brian Irwin for provision of P-I data, George White for his assistance with graphics and Linda Payzant for help with the satellite data (Bedford Institute of Oceanography, Nova Scotia). We wish to thank those scientists at NASA who made available the satellite data for this study (Tran et al. 1992). We wish also to thank the officers and crew of the RRS 'Discovery', and scientific colleagues from the Plymouth Marine Laboratory, for their help at sea. We would especially like to thank Malcolm Woodward for provision of nutrient data, Linda Gilpin and Graham Savidge for provision of primary production datâ. Also thanks to Polly Machin, at BODC for her help and efficiency. Thanks to Gordon Henry, Newcastle University for his help with the ${ }^{15} \mathrm{~N}$ analyses. The work presented in this paper was supported by the U.K. Natural Environment Research Council (Grant No. GR3/09344); the Office of Naval Research; the National Aeronautics and Space Administration; the Department of Fisheries of Oceans, Canada and the Natural Sciences and Engineering research Council. This work was part of the Canadian Joint Global Ocean Flux Study.

\section{LITERATURE CITED}

Angel MV (1984) Marine science of the northwest Indian Ocean and adjacent waters. Deep-Sea Res 31:573-1035

Banse K, English DC (1994) Seasonality of coastal zone colour scanner phytoplankton pigment in the offshore oceans. J Geophys Res 99 (C4):7323-7345

Bauer S, Hitchcock GL, Olson DB (1991) Influence of monsoonally-forced Ekman dynamics upon surface-layer depth and plankton biomass distribution in the Arabian Sea. Deep-Sea Res 38(5):531-553

Bird RE (1984) A simple, solar spectral model for direct-normal and diffuse horizontal irradiance. Sol Energy 32:461-471

Brock JC, MCClain CR, Luther ME, Hay WW (1991) The phytoplankton bloom in the northwestern Arabian Sea during the southwest monsoon of 1979. J Geophys Res 96 (C11):20623-20642

Brock JC, Sathyendranath S, Platt T (1993) Modelling the seasonality of subsurface light and primary production in the Arabian Sea. Mar Ecol Prog Ser 101:209-221

Brock JC, Sathyendranath S, Platt T (1998) Biohydro-optical classification of the northwestern Indian Ocean. Mar Ecol Prog Ser 165:1-15

Burkill PH, Mantoura RFC, Owens NJP (1993) Biogeochemical cycling in the northwestern Indian Ocean: a brief overview. Deep-Sea Res II 40(3):643-649

Bury SJ, Owens NJP, Preston T $(1995){ }^{13} \mathrm{C}$ and ${ }^{15} \mathrm{~N}$ uptake by phytoplankton in the marginal ice zone of the Bellinghausen Sea. Deep-Sea Res II 42:1225-1252

Dugdale RC, Goering JJ (1967) Uptake of new and regenerated forms of nitrogen in primary productivity Limnol Oceanogr 12:196-206

Dugdale RC, Davis CO, Wilkerson FP (1997) Assessment of new production at the upwelling center at Point Conception, California, using nitrate estimated from remotely sensed sea surface temperature. J Geophys Res 102 (C4): 8573-8585

Dugdale RC, Morel A, Bricaud A, Wilkerson FP (1989) Modeling new production in upwelling centres: a case study of modeling new production from remotely sensed temperature and colour. J Geophys Res 94:18119-18132 
Eppley RW, Peterson BJ (1979) Particulate organic matter flux and planktonic new production in the deep ocean. Nature 282:677-680

Gordon HR, McCluney WR (1975) Estimation of the depth of sunlight penetration in the sea for remote sensing. Appl Optics 14(2):413-416

Gordon HR, Morel AY (1983) Remote assessment of ocean colour for interpretation of satellite visible imagery. A review. Springer-Verlag, New York

Hay BJ, McClain CR, Petzold M (1992) An assessment of the Nimbus-7/CZCS calibration for May 1986 using satellite and in situ data from the Arabian Sea. Remote Sens Environ 43:35-46

Karl D, Letelier R, Tupas L, Dore J, Christian J, Hebel D (1997) The role of nitrogen fixation in biogeochemical cycling in the subtropical North Pacific Ocean. Nature 388:533-538

Krey J (1973) Primary production in the Indian Ocean I. In Zeitzschel B (ed) The biology of the Indian Ocean, ecological studies, analysis and synthesis, Vol. 3. Springer, Berlin, p 115-130

Krey J, Babenerd B (1976) Phytoplankton production atlas of the international Indian Ocean expedition. Institut fü Meereskunde an der Universität Kiel

Kudela RM, Dugdale RC (1995) Estimation of new production from remotely sensed data in a coastal upwelling regime. Adv Space Res No 7, 18:91-97

Letelier RM, Karl DM (1996) Role of Trichodesmium spp in the productivity of the subtropical North Pacific Ocean. Mar Ecol Prog Ser 133:263-273

Longhurst AR, Sathyendranath S, Platt T, Caverhill C (1995) An estimate of global primary production in the ocean from satellite radiometer data. J Plankton Res 17(6): $1245-1271$

Morel A, André JM (1991) Pigment distribution and primary production in the western Mediterranean as derived and modelled from coastal zone colour scanner observations. J Geophys Res 98:14561-14576

Mueller JL, Lange RE (1989) Bio-optical provinces of the Northeast Pacific Ocean; a provisional analysis. Limnol Oceanogr 34:1572-1586

Owens NJP, Burkill PH, Mantoura RFC, Woodward EMS, Bellan IE, Howland RJM, Llewellyn CA (1993) Sizefractionated primary production and nitrogen assimilation in the northwestern Indian Ocean. Deep-Sea Res II 40(3):607-709

Pinkerton $\mathrm{MH}$, Trees CC, Aiken J, Bale AJ, Moore GF, Barlow RG, Cummings DG (1999) Retrieval of near-surface biooptical properties of the Arabian Sea from remotely sensed ocean colour. Deep-Sea Res II 46(3-4):549-569

Platt T, Sathyendranath S (1988) Oceanic primary production: estimation by remote sensing at local and regional scales. Science 241:1613-1620

Platt T, Caverhill C, Sathyendranath S (1991) Basin-scale estimates of oceanic primary production by remote sensing: the North Atlantic. J Geophys Res 96:15147-15159

Platt T, Jauhari P, Sathyendranath S (1992) The importance and measurement of new production. In: Falkowski PG, Woodhead AD (eds) Primary productivity and biogeochemical cycles in the sea. Plenum Press, New York, p 273-284

Platt T, Sathyendranath S, Longhurst A (1995) Remote sensing of primary production in the ocean: promise and fulfilment. Phil Trans R Soc Lond B 348:191-202

Editorial responsibility: Otto Kinne (Editor),

Oldendorf/Luhe, Germany
Platt T, Sathyendranath S, Caverhill CM, Lewis MR (1988) Ocean primary production and available light: further algorithms for remote sensing. Deep-Sea Res 35:855-879

Qasim SZ (1982) Oceanography of the northern Arabian Sea. Deep-Sea Res 29:1041-1068

Saijo J (1973) The formation of the chlorophyll maximum in the Indian Ocean. In: Zeitzschel B (ed) The biology of the Indian Ocean. Springer, Berlin, p 171-173

Sathyendranath S, Platt T (1989) Remote sensing of ocean chlorophyll: consequence of non-uniform pigment profile. Appl Optics 28:490-495

Sathyendranath S, Platt T (1993) Remote sensing of watercolumn primary production. In: Li WKW, Maestrini SY (eds) Measurement of primary production from the molecular to the global scale. ICES Marine Science Symposia, Copenhagen 197:236-243

Sathyendranath S, Gouveia AD, Sheyte SR, Ravindran P, Platt $T$ (1991) Biological control of surface temperature in the Arabian Sea. Nature 349:54-56

Sathyendranath S, Platt T, Horne EPW, Harrison WG, Ulloa O, Outerbridge R, Hoepffner N (1991) Estimation of new production in the ocean by compound remote sensing. Nature 353:129-133

Sathyendranath $S$, Longhurst $A$, Caverhill CM, Platt $T$ (1995) Regionally and seasonally differentiated primary production in the North Atlantic. Deep-Sea Res I 42(10): 1773-1802

Sathyendranath $S$, Platt $T$, Stuart $V$, Irwin BD, Maass $H_{\text {, }}$ Savidge G, Gilpin L, Platt T (1999) Seasonal variations in bio-optical properties of phytoplankton in the Arabian Sea. Deep-Sea Res II 46(3-4):633-653

Savidge $G_{1}$ Gilpin L (1999) Seasonal influences on sizefractionated chlorophyll a concentrations and primary production in the north-west Indian Ocean. Deep-Sea Res II 46(3-4):701-723

Schott F, Swallow JC, Fieux M (1990) The Somali Current at the Equator: annual cycle of currents and transports in the upper $1000 \mathrm{~m}$ and connection with neighbouring latitudes. Deep-Sea Res 37:1825-1848

Tran A, Smith VE, Hyon J, Evans R, Brown O, Feldman G (1992) Satellite-derived multi-channel sea-surface temperature and phytoplankton pigment concentration data: A CD-ROM set containing monthly mean distributions for the global oceans, JPL D-1035-1 (internal document), Jet Propulsion Laboratory, Pasadena, California. Document (015.D001) provided with data

Watts LJ, Owens NJP (1999) Nitrogen assimilation and the $f$-ratio in the north western Indian Ocean during an intermonsoon period. Deep-Sea Res II 46(3-4):725-743

Williams PJ LeB (1998) The balance of plankton respiration and photosynthesis in the open oceans. Nature 394: $55-57$

Woodward EM, Rees AP, Stephens JA (1999) Influence of the southwest monsoon upon the nutrient biogeochemistry of the Arabian Sea. Deep-Sea Res II 46(3-4):571-591

Wyrtki K (1971) Oceanographic atlas of the international Indian Ocean expedition. National Science Foundation, Washington, DC

Yentsch CS (1965) Distribution of chlorophyll and phaeophytin in the open ocean. Deep-Sea Res I 12:653-666

Zeitzschel B (1973) The biology of the Indian Ocean. Ecological studies. Analysis and Synthesis, Vol 3. Springer, Berlin, p 549

Submitted: July 20, 1998; Accepted: December 12, 1998

Proots received from author(s): June 10, 1999 